\title{
The Republic of Letters and the Origins of Scientific Knowledge Commons
}

\author{
Michael J. Madison
}

Cite as: Madison, Michael J. 2021. "The Republic of Letters and the Origins of Scientific Knowledge Commons." In Governing Privacy in Knowledge Commons, edited by Madelyn Rose Sanfilippo, Brett M. Frischmann, and Katherine J. Strandburg, 151-184. Cambridge: Cambridge University Press.

\subsection{INTRODUCTION}

Science in the twenty-first century is public and open, both by design and by ambition. Declaring that the production and distribution of scientific research should be freely circulated and accessible does not make it so, of course. Claims of proprietary right and exclusivity magnify the complexities of coordinating multiple researchers, research enterprises, and associated disciplinary conditions and technology tools (Royal Society (Great Britain), Science Policy Centre, and Royal Society (Great Britain) 2012; National Academies of Sciences, Engineering, and Medicine (U.S.) et al. 2018). To understand what may be called ecological relationships among practices of openness and practices of exclusivity in a particular scientific setting, a commons governance rubric may be used to collect for analysis actors, resources, and rules that govern the production of scientific knowledge. The rubric used here is the knowledge commons research framework, sometimes abbreviated "GKC" after the title of the initial collection of case studies describing and applying it (Frischmann, Madison, and Strandburg 2014b). Chapter 1 of this volume lays out the knowledge commons framework in detail.

In brief, knowledge commons refers to governance of shared knowledge and information resources by members of a community. It focuses on institutional design rather than pooled resources as such (Frischmann, Madison, and Strandburg 2014b). This chapter advances application of the knowledge commons research framework by calling attention to additional dimensions of commons governance in scientific enterprises, dimensions that define and apply distinctions between publicness, on the one hand, and privacy and private and personal interest, on the other hand. As its central case, the chapter turns the clock back to the origins of modern scientific research and communications, in the Republic of Letters of the late sixteenth, seventeenth, and early eighteenth centuries.

The goal here is partly to apply the knowledge commons framework carefully to the Republic of Letters, a historical case that has previously been assumed to represent a significant commons institution, and partly to use that careful application to explore dimensions of that commons institution that are better regarded as its private-facing elements rather than its more celebrated public- 
facing elements. The Republic of Letters (in Latin, Respublica literaria) is the name given, then and today, to a large, distributed network of researchers and correspondents centered in Europe, which developed and advanced a sophisticated and robust system of knowledge exchange via letters and printed publications. The Republic of Letters is usually identified as the bridge between medieval and Renaissance scientific investigations and a system of research and communications that is recognizably modern, if only in its rough outline (Darnton 2003; van Miert 2016). That "Republican" system of communications, coupled with the related emergence of formal scientific institutions such as academies and journals, merged into the Scientific Revolution and the Enlightenment and eventually into modern scientific disciplines, research universities, and the present so-called Republic of Science (Polanyi 1962).

The suggestion here is that this parade of seeming progress was accompanied by important development of and dependence on public sharing of private, personal interests and resources. That suggestion complements typical accounts of scientific research and communications that locate their critical value and virtue principally in their publicness. That public character comes to the fore whether science is understood to contribute to collective identity and selfdetermination, or to economic well-being, or both (Merton 1942; Stokes 2011). The role of privacy is acknowledged; Bruno Latour's work highlights the significance of private spaces, such as laboratories and libraries, in the day to day activity of scientists (Latour and Woolgar 1986). Scholars have described the transition between the private and the public sometimes as a story of complementary practice, and sometimes, as in the well-documented history of Louis Pasteur's work, as a story of conflict between private and public-facing aspects of scientific research (Geison 2014).

The knowledge commons framework applied here offers a way to integrate these points of view. Not all research universities, research institutes, or corporate research and development organizations operate in the same way. Institutional settings vary; patterns of scientific research evolve. Normative practices develop and change, suggesting that norms may be violated as well as followed. Understanding the attributes and influences of particular institutional settings can lead to understanding different patterns of knowledge production and dissemination. The knowledge commons framework provides a fruitful way to tease out that understanding on a case by case basis.

In sum, the Republic of Letters is a case of enormous historical interest in its own right, with both economic historians and historians of science continuing longstanding efforts to grasp its scope and its significance (Grafton 2008; Mokyr 2017). The case also offers lessons in the interweaving of publicness and privacy in commons governance that may be useful, even critical, in understanding and guiding the evolution of modern science. 
The chapter begins briefly in Section 6.2 with an introduction to open science, a contemporary rhetorical and institutional construct that highlights both new opportunities and continuing dilemmas associated with scientific research. Its purpose is to prefigure the review of the Republic of Letters in commons terms by illustrating the modern relevance of the historical case study. Section 6.3 describes and examines the Republic of Letters. Its purpose is not to dig anew into the dynamics of the Republic but instead to analyze the Republic of Letters via the knowledge commons framework. The chapter relies on a critical parsing of the diverse body of secondary literature surrounding the Republic of Letters, rather than on revisiting primary sources. This section contrasts the knowledge commons analysis briefly with other analyses that do not adopt a commons governance perspective (or a governance perspective of any sort) or that apply a commons label but without doing so in a systematic way. Section 6.4 highlights attributes of the Republic of Letters that are properly characterized as personal or private resources and interests, suggesting connections among different types of information and knowledge resources in the Republic's knowledge-sharing ecology. Section 6.5 suggests some implications and applications of the case study to modern open science.

\subsection{Modern Open SCIEnCE AS SCIENTIFIC KNOWLEdGe Commons}

The Republic of Letters is a critical knowledge commons case precisely because many of the challenges and dilemmas to which the Republic responded correspond to challenges and dilemmas that confront modern scientific research.

In the early twenty-first century, researchers around the world have undertaken social movements and related organizational and bureaucratic efforts to advance the concept of "open science." These efforts are motivated by the idea that broad public dissemination of scientific research results, to both expert and non-expert audiences, is the best way to advance the public interest through science. That proposition has its roots in the Republic of Letters. Open science represents a novel vision that is timely in light of the confluence of emerging social, economic, and technology conditions. That confluence resembles in broad outline the circumstances that held at the outset of the Republic of Letters.

\subsubsection{Open Science Described}

In the twenty-first century, the emerging conditions that constitute open science are high speed computer networks, data storage and data processing capabilities, virtual communications, multi-disciplinary and trans-disciplinary research teams, heterogeneous funding sources, and the power of commercial scientific publishers. A recent report of the National Academies described open science and its foundations as follows: 
Openness and sharing of information are fundamental to the progress of science and to the effective functioning of the research enterprise. The advent of scientific journals in the 17 th century helped power the Scientific Revolution by allowing researchers to communicate across time and space, using the technologies of that era to generate reliable knowledge more quickly and efficiently. Harnessing today's stunning, ongoing advances in information technologies, the global research enterprise and its stakeholders are moving toward a new open science ecosystem. Open science aims to ensure the free availability and usability of scholarly publications, the data that result from scholarly research, and the methodologies, including code or algorithms, that were used to generate those data (National Academies of Sciences, Engineering, and Medicine (U.S.) et al. 2018).

An analogous Royal Society report outlining strategies to advance open science expressed similar optimism. It used language cautioning policymakers to realize novel opportunities without sacrificing the integrity of scientific communities as self-policing enterprises, without losing sight of the importance of scientific understanding by non-scientists, and without undermining legitimate interests in private action and privacy of research subjects and results:

Successful exploitation of these powerful new approaches will come from six changes: (1) a shift away from a research culture where data is viewed as a private preserve; (2) expanding the criteria used to evaluate research to give credit for useful data communication and novel ways of collaborating; (3) the development of common standards for communicating data; (4) mandating intelligent openness for data relevant to published scientific papers; (5) strengthening the cohort of data scientists needed to manage and support the use of digital data (which will also be crucial to the success of private sector data analysis and the government's Open Data strategy); and (6) the development and use of new software tools to automate and simplify the creation and exploitation of datasets. The means to make these changes are available. But their realisation needs an effective commitment to their use from scientists, their institutions and those who fund and support science (Royal Society (Great Britain), Science Policy Centre, and Royal Society (Great Britain) 2012).

\subsubsection{Open Science Dilemmas and Commons Strategies}

Both reports from which these quotations are taken, and the advocates and organizers of open science efforts generally, describe social dilemmas that are recognizable to commons governance researchers. The important questions are not "how and why do researchers produce scientific knowledge?," but instead how the multiple components of "science" and "scientific knowledge" come to be pooled in the first place, how they are shared with various constituencies, and how those constituencies draw on those pooled resources. 
Scientific expertise, research tools, research results, and data themselves each constitute important commons opportunities (Borgman 2015).

Specifically, in open science, how do (and should) individual researchers both protect important personal interests in reputation, priority, integrity and accuracy, and autonomy, while yielding information to the body of knowledge that constitutes both their scientific discipline(s) and the storehouse of society's knowledge generally? How do scientific research results produced by one researcher come to be accepted as knowledge by others, and then acted on, both in the development of further knowledge (or, possibly, different knowledge) and in the development of useful applications? How does one researcher know whether to shape results in the direction of industrial or commercial application, or to guide results in the direction of broader sharing with the field (usually, open or public)? The directional arrow need not proceed from "basic" insights to "applied" know how and devices. The directional arrow may run in the opposite direction, or it may run in multiple directions at once (Stokes 2011; Frischmann 2012). The resulting insight is that open science is a challenge of managing an ecology of knowledge and information resources, rather than a challenge of managing a production line. Simply labelling everything "open" is a starting point, rather than a conclusion.

Proceeding from that starting point is a matter of empirics and pragmatics, as much as if not more than ideology (David, den Besten, and Schroeder 2008). Pragmatically, contemporary open science, or scientific knowledge production, likely does and should operate as commons, meaning structured production and dissemination of shared knowledge by members of overlapping communities. While a detailed investigation of open science as knowledge commons must await additional research, for now it is important to observe that those modern themes - publicness and openness; community; accuracy, integrity, and trust in pooled resources; and privacy and private interests in the accumulation of knowledge - also informed the emergence of the Republic of Letters, centuries ago. The next sections address the Republic of Letters as knowledge commons and consider whether the lessons of history might help inform modern scientific practice.

\subsection{The Republic of LeTters AND the ORIgins of SCIENTIFIC KNOWLEDGe Commons}

The Republic of Letters is an aggrandizing, idealizing label given to a network of correspondents and correspondence that was the first recognizably modern scholarly and scientific research enterprise, in its emphasis on public distribution of and reasoned debate concerning information collected in and about the world (Grafton 2009). An adage attributed to the Dutch Renaissance humanist Desiderius Erasmus Roterodamus (Erasmus) (1466-1536) distilled in a single phrase the noble spirit and ambition of the enterprise: "All the property of friends 
is held in common" (quoted in (Grafton 2009)). ${ }^{1}$ In short: knowledge, shared with sociability among colleagues. In the languages of the time, it was the Respublica literaria (Latin, from Res Publica Litterarum) and the République des lettres (French).

As an intellectual enterprise, the Republic of Letters constituted a lengthy postscript to the late Renaissance and precursor to the Enlightenment and eventually to modern science (Fumaroli 1988, 2018). Across Europe and eventually in North America and Southeast Asia (Hindley 2013), thousands of experimentalists, observationalists, natural philosophers, and collectors - men of letters, philosophes, savants, a self-identified intellectual aristocracy operating outside the formal boundaries of nation, state, and church - documented their studies in letters and distributed them in far flung correspondence networks. The "Letters" of the title refers not to postal correspondence, however, but to the literary character of the public exchange, conducted not only through letters but also through books, pamphlets, and other printed publications. The first scholarly journals were established during this period, in France (the Journal des sçavans, later renamed the Journal des savans and then the Journal des savants) and in England (the Philosophical Transactions of the Royal Society).

The product of this intellectual exchange was a large, distributed selfgoverning collective of early scientists and philosophers, bound to one another informally but normatively by a well-understood, if imperfectly enforced, system of rules and guidelines. Written correspondence was linked to in-person visits and conversation and eventually to the formation of early learned societies, scientific academies, salons, and scholarly journals. The informal and formal versions of all of these are typically clustered by historians under the same "republican" label, as a cluster of institutions and practices in which mostly autonomous individuals aligned themselves and their efforts relative to one another. With the rise of national interests, early steps toward the formation of modern academic disciplines, and re-institutionalization of research in precursors to modern universities and research institutes, the Republic of Letters as such came to an end. Its shared values gave rise to what Michael Polanyi labeled the still-ongoing Republic of Science.

The era of the Republic of Letters had no fixed beginning or end. Historians commonly point to the mid-sixteenth century as an approximate start date, identifying Erasmus himself as a pivotal figure in the transition from the Renaissance to the Republic, and point to the mid-eighteenth century and the end of the Ancien Régime as the time of transition away from the Republic toward what we know as the Enlightenment. Voltaire and others combined the outwardor public-facing spirit of the Republic with powerful interests in social progress (Mokyr 2017). The journal, as the printed legacy of the Republic of Letters, was

\footnotetext{
1 Eden translated the adage, which Erasmus adapted from Pythagoras, as "friends hold all things in common." (Eden 2001).
} 
supplemented by the signature intellectual ambition of the Enlightenment, the Encyclopedie.

\subsubsection{The Republic of Letters as a Knowledge Institution}

The name "Republic of Letters" first came into broad circulation via publication in Amsterdam of the journal Nouvelles de la République des Lettres by the French philosopher and critic Pierre Bayle, beginning in 1684. Use of the title was unremarked, implying both its currency and a collective understanding regarding its existence. (References to a Republic of Letters go back as far as the early 1400s, and the idea of a Res Publica extends at least as far back as Plato (Maclean 2008).) Some scholars periodize the Republic of Letters, emphasizing efforts in natural philosophy (science) in the seventeenth century, and a turn to philosophy in the eighteenth century, leading to the Enlightenment (Goldgar 1995; van Miert 2016). The historian Peter Gay drew a sharp distinction between the Republic of Letters and the Enlightenment, interpreting the former as essentially backwardlooking and unimportant and the latter as forward-looking and critical to progress (Gay 1966). Others see fewer clear divisions (Brockliss 2002).

The Republic witnessed the contributions of a large number of celebrated philosophers, critics, natural philosophers, astronomers, chemists, physicians, mathematicians, botanists, geographers, historians, theologians, and many others, to use a number of modern disciplinary categories, including Newton, Hooke, and Leibniz; Huygens and Linnaeus; Locke, Hobbes, Hume, Descartes, Vico, Le Clerc, and Benjamin Franklin. Of course, the Republic included thousands of men, and some women, with local and regional identities, whose intellectual legacies are far less notable than the thousands of letters they left behind (Brockliss 2002).

That abbreviated summary offers only a brief entrée into a complex subject: How and why did the Republic of Letters originate, operate, and end (Goodman 1996; Darnton 2003; David 2008; Grafton 2008; Fumaroli 2018)? If, as historians and economists generally agree, the Republic of Letters constituted and created an infrastructure for scientific knowledge production and intellectual communication, in what respects - if any - can it be counted a success? This chapter identifies some leading lines of scholarly thought on those questions. They are, also, questions to which the knowledge commons research framework offers some additional and perhaps novel responses.

Preliminarily, the premise of the inquiry - that the Republic of Letters involved collective or collaborative governance of one or more knowledge resources, which can be usefully assessed via the knowledge commons framework - deserves attention. Was the Republic of Letters an institution in the sense that the knowledge commons framework is best directed to institutional cases, for use in eventual comparative institutional analysis? 
I argue that it is, given the definition of institution offered by the economist and Nobelist Douglass North: the rules of the game of a society devised by humans and shaping human behavior (North 1990). To similar if not identical effect is the concept of the institution developed in modern sociology: institutions as stable behavioral patterns that reflect the coordinated behavior of individuals and organizations, where the relations define the actors rather than the other way around (DiMaggio and Powell 1983; Powell 1990; Padgett and Powell 2017).

The difference between the two definitions, the former focusing more on rules that guide or determine patterned behavior and the latter focusing on rules that reflect patterned behavior, is not determinative here. What matters is that the Republic of Letters was an institution in either sense, in that it produced and relied on a well-understood set of human-created informal norms to determine outcomes among a group of people who significantly self-identified with the enterprise in its own time. The Republic of Letters was not a small community, nor was it clearly or precisely bounded in terms of membership, in terms of time, or in terms of place. It was, to use Anthony Grafton's phrase, a "strange imaginary land" (Grafton 2008), but it was no less real to its citizens than a modern state. The Republic of Letters was an "imagined community" of the sort described by Benedict Anderson (Anderson 1983; Darnton 2003). Ostrom and others speak credibly of knowledge and modern science as subjects of commons governance; it is appropriate to adopt the same framework for a critical moment in scientific history. The economic historian Joel Mokyr draws the same conclusion, aligning the Republic of Letters with Ostrom's view of knowledge as a commons (Mokyr 2017, 2011-2012). In his work that proposition is essentially a final judgment. Here, it is a starting point.

\subsubsection{Resources, Actors, and Dilemmas in the Republic of Letters}

Histories of the Republic of Letters often adopt the vocabulary of modern knowledge practice: the Republic engaged scientists in the construction of modern science (Daston 1991), building on the sixteenth century and early seventeenth century discoveries of the Scientific Revolution, beginning in the sixteenth century (Westfall 1977). Yet the word "scientist" was not coined until the 1830s, by William Whewell. Retrospective application risks imposing a more discipline-specific and rigorously methodological character on citizens of the Republic than was actually the case. The knowledge commons framework begins with investigations into the actors, resources, and dilemmas associated with a governance enterprise. In the case of the Republic of Letters, a central, common theme is their heterogeneity.

\subsubsection{Actors}


The central actors in most commons systems are the producers and consumers of shared resources. In this instance, the principal players in the Republic of Letters, citizens and republicans, were the educated elite, the intellectuals and scholar participants and correspondents themselves. With thousands of contributors and a broad range of substantive knowledge in circulation, it is impossible to describe a standard or canonical actor. They were, on the whole, independent of the sort of institutional association that characterizes modern researchers, who are typically employed in universities, research institutes, or industrial enterprises. Exceptional cases, such as Newton's chair at Cambridge, are well known. In addition to their stand-alone status, they were typically characterized by intellectual catholicity. One of the points of the Republic of Letters was that it sustained intellectual discourse across the full breath of emerging knowledge. Admission to this company of scholars required investment in basic intellectual tools and signing on, by participation, to the Republic's code of conduct. Letters composed in line with the accepted style gracious introduction, brief polite personal commentary, description of observations, and perhaps an enclosed table, or drawing, or other supplement (Atkinson 1999) - obliged a recipient to reciprocate. Personal visits framed by comparable rituals of civility likewise offered entrée to the Republic. Anthony Grafton wrote:

[T] hen as now, scholar did not rhyme with dollar. But they looked for learning, for humanity, for generosity, and they rewarded those who possessed these qualities. Any young man, and more than a few young women, could pay the price of admission. Just master Latin - and, ideally, Greek, Hebrew, and Arabic; become proficient at what now seem the unconnected skills of mathematics and astronomy, history and geography, physics and music; turn up at the door of any recognized scholar from John Locke in London to Giambattista Vico in Naples, bearing a letter from a senior scholar, and greet your host in acceptable Latin or French - and you were assured of everything a learned man or woman could want: a warm and civilized welcome, a cup of chocolate (or, later, coffee); and an hour or two of ceremonious conversation on the latest editions of the classics and the most recent sightings of the rings of Saturn (Grafton 2008).

Grafton's direct reference to status without wealth means that a second group of actors also played critical roles: patrons. Social elites, lords and noblemen, who did have wealth and status but not expertise, were largely responsible for retaining and supporting the citizens of the Republic on behalf of their families and estates. Scholars were compensated with both money and credit; reputation was a critical part of the Republic's circulating currency (Biagioli 1989, 1990; David 2008). The patronage system was central but not universal. Some participants in the Republic of Letters supported themselves by professional practice (physicians, often) and some by other, independent means, such as printing (including, in colonial America, Benjamin Franklin). 
A third class of actors emerged as the Republic evolved and took on organizational trappings: the founders, convenors, and coordinators of learned societies, academies, salons, and journals. These formalized some face to face interaction among citizens of the Republic and also structured selection and dissemination of scholarly correspondence to (potentially) wider audiences. Some societies and academies, hosting face to face presentations and conversations, had state sponsorship, such as the Royal Society (England), founded in 1660, and the French Academy of Sciences (Académie des sciences), founded in 1666. Some did not, such as the Academy of Sciences Leopoldina (Deutsche Akademie der Naturforscher Leopoldina, originally the Academia Naturae Curiosorum) (Germany), founded in 1652. Journals emerged during the same era but often had autonomous or semi-autonomous origins before, in some instances, merging with society or academy hosts. (In their appearance and content, early journals were more like printed pamphlets of letters than modernseeming collections of research articles.) The journal of the Royal Society, Philosophical Transactions, was established in 1665 as a separate venture of the Society's secretary, Henry Oldenburg, and only later became an official publication of the Royal Society. A third organizational form, the salon, existed side by side with these two and was especially hospitable to women, particularly in French cities (Goodman 1996).

\subsubsection{Resources}

Commons analysis often speaks of managing a single, shared, or pooled resource, holding open the possibility that the resource may be divided physically, culturally, or analytically into resource units that may be contributed to or extracted from the resource, or at least consumed. A fishery has fish; a forest has trees; a patent pool has patents. Knowledge commons studies to date suggest that knowledge commons involve multiple pooled knowledge and information resources, usually intangible and immaterial, but often with links to or overlaps with material objects and systems.

In the Republic of Letters, that complex pattern holds. The logical place to start is the physical letters themselves, transported relatively safely and securely via the system of mail delivery emerging via Continent-wide expansion and consolidation of private, regional systems and courier services (Mokyr 20112012), improved transportation networks (roads and seas), and - the Thirty Years' War aside (1618-1648) - relative safety for travelers (Merton 1938). This physical infrastructure of correspondence networks converged with the invention of movable type in the latter part of the fifteenth century and the emergence of a class of printers and publishers. The coevolution of the material and immaterial aspects of the Republic of Letters as communications network aligns with the co-evolution of material (instruments) and immaterial 
(methodological and epistemological) aspects of scientific research itself, a topic revisited later.

The technological and organizational infrastructure of printing and publishing converged with commercial interests in the adoption of both the earliest patent statute (the English Statute of Monopolies, 1624) and, more important here, the earliest copyright statute (the English Statute of Anne, 1710). The latter gave early, formal meaning in law to a key attribute of the Republic of Letters. Copyright law documented the concept of piracy as misappropriation of a form, such as a printed work, in which knowledge and information were communicated (Johns 2009). Knowledge itself, by contrast, was currency to be shared. Law formalized a boundary between what was proprietary (and propriety) and what was piracy, or impoliteness, that was defining appropriate conduct within the Republic of Letters itself. Knowledge was to be shared; printed matter could be owned.

The central shared resource in the Republic of Letters was knowledge itself, and especially the beginnings of what today we would characterize as scientific knowledge (Daston 1991; Darnton 2003; David 2008; Grafton 2009). Yet this pooled resource should be treated carefully, so that dilemmas and governance solutions can be mapped in some detail. The practices of the Republic of Letters reflected and reinforced sets of shared beliefs, values, and commitments as much as the content of what, today, we call science.

The polymathic character of many of the citizens of the Republic and the multidimensional character of the letters they shared - possibly blending descriptions of specimens, collections of objects, or observations; the results of experiments; interpretations of historical events, geography, or chronology, and more - suggest that what was pooled as a knowledge resource was not, in the first place, the content of early scientific disciplines, even if individual contributions constituted forms and products of early science. The information shared and then disseminated was a form of shared infrastructure relative to the later development of the intellectual content of scientific fields. In its own time, the primary function of the Republic of Letters was not solely to generate a resource or set of resources consisting of propositional knowledge.

Implicit in the Republic, instead, were several layers of shared knowledge of other sorts, epistemological and methodological, mapping in certain respects onto the distinction between codified knowledge (knowledge of) and tacit knowledge (knowledge how) later drawn by Michael Polanyi (Polanyi 1966). There is an overlap at this point between matters of knowledge and matters of trust: the citizens of the Republic had to manage both the contents of shared communications and also the social and cultural skills needed to critically assess knowledge supplied by distant and possibly unknown sources. The resources at stake should be characterized as both. Drawing out their nuances most effectively involves borrowing briefly from two other scholarly fields, and drawing some 
preliminary links between the character of the knowledge resources and the character of relevant social dilemmas.

One source is communications theory. Developing governance mechanisms through the Republic of Letters required practical and conceptual mechanisms for accuracy and verifiability and for sharing information about practices and results, including both successes and failures. Practically, information had to be communicated accurately and reliably. A shared syntax of scientific communications had to be developed, in the following sense: "is this a recognizable scientific communication?" A shared semantics of scientific communication had to be developed, in the following sense: "do I understand the scientific content of this communication?" A shared pragmatics of scientific communication had to be developed, in the following sense: "Given that I understand the scientific content of this communication, do I understand how to act on it appropriately?" The questions go to cognition. Participants in the Republic of Letters had to establish ways of learning by which information communicated by a distant correspondent would be incorporated into a body of knowledge that could and would be acted upon in mostly consistent ways by recipients. "Science" as a practice had to be developed and sustained from individual thought and behavior, much in the same way that "law" as a practice had to be developed and sustained (Shapiro 1972). That summary highlights the role of the individual and hints at the importance of dilemmas associated with aggregating individual practices into a shared knowledge resource.

A second source is the domain of Science and Technology Studies (STS) research that focuses on social epistemology in the history and philosophy of science. The questions go to patterns of social life as they bear on cognition. Relevant perspectives include those suggested by Robert Merton on the role of priority in advancing science as a collective or communal activity (Merton 1957), Thomas Kuhn on the collective constitution of shared scientific paradigms (Kuhn 2012), and Bruno Latour and Steve Woolgar on the construction of scientific facts via processes that represent laboratory practice in text and other forms (Latour and Woolgar 1986). In distinct but overlapping ways, these scholars bring out techniques by which scientists identify as scientists and identify their work as contributing to a shared enterprise. Scientific knowledge is simultaneously individual and collective (Spender 1996). Research on organizational design and organizational learning bring similar questions to bear on formal workspaces (Brown and Duguid 2000; Hutchins 2000).

Applying both sources to the Republic of Letters yields the conclusion that citizens of the Republic shared several distinct knowledge resources, in addition to scientific knowledge itself: First, the idea that knowledge of the world could be obtained via observation, analysis, and systematic study. Second, the idea that this knowledge could be recorded and codified in forms that were intelligible to those who did not generate those observations first-hand. Third, the idea that knowledge of the world could be increased and improved via dialogue with 
fellow citizens. Fourth, the idea that there existed virtue and value associated with publicizing scholarly information, both in the sense that citizens of the Republic subscribed to the belief that public dissemination of knowledge was useful instrumentally in order to sort good knowledge (accurate, or true) from bad, and also in the sense that the citizens shared a commitment to intellectual and scholarly sociability itself. Both senses were expressed in letters, codifying and reinforcing the existence of that knowledge pool as a tacit resource, that is, as a matter of shared, distributed cognition (Greif and Mokyr 2016).

In sum, the purposes of the Republic of Letters were at least two-fold: one was to produce a shared knowledge base that civil society could draw on as part of social, cultural, and political progress; a second was to produce the communalism that has been the hallmark of scientific practice ever since.

\subsubsection{Dilemmas}

The foregoing summary of actors and resources suggests directly that the standard framing of a shared resource as a "tragic commons" social dilemma, in which individual interests of choice-oriented, self-regarding individual actors dominate collective welfare, is insufficient and perhaps altogether inapt in this instance.

For example, it is possible to summarize the relevant dilemma in brief as follows: As the Scientific Revolution developed in the fifteenth and early sixteenth centuries, European societies lacked conceptual and material systems for accumulating and distributing technological innovation and scientific knowledge. An epistemology of facts, progress, and secular knowledge grounded in experience, so-called Baconian science or the scientific method, was still in formation following publication of the Novum Organum in 1620. Individual means and motivations for sharing knowledge were diverse (at best) and limited (at worst). Institutions for authenticating, documenting, distributing, and collecting scientific knowledge were scattered and splintered, between medieval universities and the beneficiaries of noble patronage, particularly in Renaissance Italy, and in some respects (printing and publishing, and learned societies, and peer assessment) were non-existent. In time, but comprehensively, the Republic of Letters addressed each of these challenges.

Yet that summary is too simple. The knowledge setting at hand may represent multiple, overlapping dilemmas, with different attributes and different possible solutions, rather than a single problem. A more nuanced review of social or collective dilemmas in the Republic of Letters context is the following.

As to the individual scholars and their production of knowledge, one social dilemma had to do with the integrity of the intellectual content itself. How would experiments and observations at any scale be acknowledged as parts of a program of Baconian science (Greif and Mokyr 2016)? The concept of assessing the relationship between nature and an examination of nature, which we know 
as the problem of objectivity, was in development. Methods for describing that relationship in codified form, in text and image, were in development. Peer review did not exist, as we understand its modern form (Baldwin 2017, 2018), even if learned societies and journals implemented early versions of assessment and refereeing systems (Zuckerman and Merton 1971). The dilemma posed both a question of assessing the work of a single scholar, and more importantly a question of how to aggregate that scholar's demeanor relative to his own work into a collective resource: trust in knowledge, or trust in science. How would conflicts and disputes over different interpretations be resolved, and the results synthesized into knowledge?

Deeper dilemmas operated as well. The concept of knowledge as good in itself, culturally, had to be developed. The citizens' shared commitment to the public character of scholarly society, also a knowledge resource, was undoubtedly constructed from a vast and therefore heterogeneous population of contributors. That had motivational dimensions as well as the epistemological implications just mentioned. In a distributed, open network such as this one, the problem of motivation typically is not that everyone is selfish, but rather than many people are selfish, many people are not, and most people exhibit a mix of self-regarding and other-regarding behaviors (Benkler 2017). Diversity is demonstrated not only from individual to individual but also from place to place and from time to time. Local and regional practices diverged even with respect to similar scholarly questions; how was it possible to speak of "the" Republic of Letters, a trans-national practice, rather than practices in London, or Paris, or Amsterdam (Daston 1991)?

At both levels, with respect to the knowledge in production and circulation and with respect to the cluster of values that was needed to sustain its circulation, the essence of the resource, as a belief system or set of shared values expressed in a system of material practice, was a classic public good, in economic terms: something that is non-rival, non-depletable, and non-excludable. The relevant social dilemma was and is how a shared commitment to producing that knowledge, to the progress of knowledge, to its publicness, and to community could be constructed and sustained out of such a fabric of diverse sources.

At an even deeper level of behavior, there was the dilemma of individual or personal investment in developing expertise and conducting research when returns to those investments were uncertain. The patronage relationship solved this problem for many citizens of the Republic. The emerging economy of reputation and status associated with participation in the Republic also contributed to a solution for many. There was no "tragic" risk of overconsumption or depletion. There were risks of undersupply (insufficient commitment) and/or defection or corruption. Participants might not follow through on expectations of reciprocal participation, or might supply the literary network with material not produced in good faith, or might convert shared knowledge or knowledge subject to a duty to share to personal or private benefit. 
As to the patrons, the dilemma is framed best in principal/agent terms. The Republic of Letters patronage system evolved out of patronage relationships in the Italian Renaissance (David 2008), but the codified products of the patronage relationships acquired a new, public, shared dimension. It is fair to begin by assuming that patrons, as principals, were motivated to invest in the first place primarily by the prospect of securing returns for themselves, paying artists and engineers, as agents, to produce works to benefit the patron himself. If, as the Republic of Letters evolved, the agents (now constituted as a broad class of scholar intellectuals) shared their works publicly, beyond the patron/scholar setting, the prospect of the patron's benefit might have been reduced. Perhaps not; on a case by case basis, one would need to explore the extent to which public sharing of the knowledge diminished the patron's ability to retain a valuable benefit. At a system level, however, a critical dilemma appears to be the willingness of patrons to invest in the circulation of knowledge that did not clearly benefit them.

As to the founders and convenors of academies, societies, and journals, social dilemmas were at least two-fold. One dilemma can be recognized as a version of the "underproduction" dilemma that characterizes some modern theorizing about intellectual property. Organizing and operating a formal enterprise such as a learned society requires both an initial capital investment and continuing expenditures of time, labor, expertise, and money. That value or its equivalent has to come from somewhere, including underwriting from the state, philanthropy, and subscription and other fees. A second dilemma resembled one of the challenges of contemporary open science: volume. The amount of information and the number of letters and other printed publications made available through the Republic of Letters created a problem of super-abundance not only for those who would try to keep up with the flow of knowledge but also for those who would curate it and organize it via journals and other publications (Blair 2010).

A separate but related dilemma was associated with the fact that the products of many of these organizations had few, if any, industrial applications. In the language of modern science, this was basic rather than applied science (Stokes 2011). Notable for their absence from the account in this chapter are craft guilds and questions of technology development, largely because the presumption of publicness that defined the Republic of Letters was reversed, elsewhere; craft innovation was presumptively secret (P. O. Long 1991).

Formal intellectual property law appeared in this history, briefly, and its role was largely to shape the boundary between circulation of knowledge inside the Republic of Letters (which was excluded from the emerging exclusivity associated with early patents and copyrights) and circulation of knowledge outside of it, and partly to guide transitions from one world to the other. For technical advances with industrial application, in practice that role required policing the distinction between basic knowledge and craft or industrial 
knowledge, and, with respect to the latter, the line between secrecy and publicity. As applied to printed matter, that meant rewarding the enterprises that circulated and re-circulated formal versions of scientific literature. The social dilemma here, in sum, was that the most visible and durable material embodiments of the Republic of Letters (academies, societies, and journals) provided forms of intellectual infrastructure, as to which the expected value and demand for the resource was diffuse and emergent and therefore difficult to aggregate for purposes of pricing in a market economy (Frischmann 2012).

\subsubsection{Arenas, Rules, and Social Norms}

The description earlier of the Republic of Letters as an imagined construct implies that defining "arenas" of interaction for knowledge commons purposes is difficult. But it is not impossible. Material environments could be located in homes, offices, shops, libraries, laboratories, observatories, coffeehouses, salons, and academy and society meeting places. The shared commitment to the circulation of knowledge could be located only in the minds of participants, as reflected in their writings and their conversations. In a sense, all of Europe was the setting for the Republic of Letters, along with epistolary connections in North America and Asia, bearing in mind the fact that it was all but invisible to those without the credentials and training that qualified them to participate.

Far more important here than material settings were the social norms that defined expected and right conduct and distinguished it from the bad. Norms in the Republic of Letters were widely documented and circulated. In what respects were they idealized and in what respects were they observed regularly in practice? In what respects were norms disciplinary, in fact?

\subsubsection{Ideals}

The literature of the Republic of Letters itself, and historians' accounts, agrees in providing rich descriptions of the duties of scholars in the Republic and the benefits to be obtained by participating in it. The values and practices of the Republic of Letters were strongly associated with the empiricism for which Francis Bacon advocated. Some scholars have treated the Republic of Letters via intellectual history as a movement motivated by idealism, prompted by and advancing Bacon's work (Eamon 1996).

Both to participants themselves and in histories of the era, participation was conditioned on observing a set of distinct, overlapping norms: (i) civility and cordiality through regular and reciprocal contact and collaboration (politeness and "taste" in Robert Darnton's account (Darnton 2003)); (ii) a commitment to the production of knowledge via empiricism and freedom of expression; (iii) evaluation by intellectual merit rather than rank or birth, and public reason; and 
(iv) religious and national tolerance and collaboration and participation across national boundaries.

\subsubsection{Practice}

The practiced Republic of Letters matched the idealized Republic of Letters to a significant degree. Historians agree that norms of civility and publicness and transnationalism were honored more in the observance than the breach; how else would the Republic of Letters have lasted as long as it did or generated as much material and as many institutions as it did, over such a large territory? The historian Lorraine Daston referred to the Republic of Letters as relying on technologies of trust and proximity (Daston 1994) - where trust referred to the credibility typically accorded to free and independent gentlemen, and proximity referred to personal ties expressed via both face-to-face interaction and the letters that embodied it.

Thus, the new academies typically welcomed foreign or "corresponding" members, and scientific correspondence and the transnational community carried on notwithstanding the disruptions of the Thirty Years' War (Daston 1991; Goldgar 1995; Goodman 1996; van Miert 2016). The disputatious and contentious character of scholarly dialogue in the preceding era, with scholastic commitments to theoretical truths competing with one another, was replaced by a system of trust in proper scholarly behavior (Dear 1992; Daston 1994). This marked the beginning of an epistemic shift. A participant who conducted himself civilly and honestly in reporting the results of Baconian investigations was accorded respect, and the work subjected to correspondence and critique within the norms of the collective. But the work was accepted because of who the producer was, rather than because of the mode of its production. The point was the person, not the object.

In a large, norm-governed, heterogeneous setting, bad behavior was hardly unheard of. Trust and proximity have been contrasted with distrust and distance (Porter 1996); in systems defined by the latter, credibility and objectivity are founded on the work itself rather than on the person. In the Republic of Letters, less of the former and more of the latter must have been part of the mix at times. Resentments and prejudices, and the absence of civil behavior and the exercise of public reason, led to well-known public disputes over priority and over credit (between Newton and Hooke, for example, and later between Newton and Leibniz). Less sensational cases typically turned on violations of civility norms, including failures of discourse (absence of language of credit or respect), and accusations of plagiarism (Grafton 2008). The resulting discipline took various forms: judgments of scientific priority, validity, and even, via conclusions as to reputation, to exclusion from the community (Daston 1991; David 2008).

Other norm-based judgments are easier to see once the polycentric or pluralistic character of the Republic of Letters is highlighted. The informal 
transnational collective had its regional and local constituents and, in academies, societies, and journals, its formal organizational complements. Ideals and practices were operating at multiple scales and in multiple places simultaneously. Karen Knorr-Cetina focuses on this multiplicity in describing scientific research as "epistemic culture" (Knorr-Cetina 1999). So, the Republic of Letters represented science, and science was represented in the Republic of Letters. What was not scientific did not make its way into the Republic of Letters in the first place or was subjected to its reason-based disciplinary system. The multitudinous character of the work of scholars meant that scholars channeled some of their work into the idealized, imagined community of the Republic, where it became part of social worlds of disputation and reasoned analysis by others (Newton, on physics) and they channeled some of their work elsewhere, where it would be received and interpreted according to different, older standards (Newton, on alchemy) (David 2008).

External forces of other sorts interfered with participants' idealism, managing the pragmatic boundaries of the Republic from the outside rather than from within. National and religious tolerance was managed in part by scholars' voluntarily moderating the content of their correspondence, and both periods of war and linguistic shifts - in particular, from Latin to French as the default language of scholars - at times depressed the volume and character of publiclycirculated works. Peter Gay directly contrasted the nobility of the ideals of the Republic of Letters with the claim that in practice, an oligarchy of landed gentry and Ancien Régime patrons rather than authors mostly directly controlled the flow and content of their letters (Gay 1966). That argument is most directly addressed to seventeenth-century practices and to works in the arts, literature, and culture rather than natural philosophy and science, but it gets to an important theme in the knowledge commons framework: If commons governance is the observed solution to one or more social dilemmas associated with a knowledge resource, is that (or was that) governance solution successful?

\subsubsection{Outcomes and Assessment}

Evaluating the Republic of Letters in comparative institutional terms is difficult for two special reasons. One is the fact that the Republic of Letters emerged and evolved over time. It was not chosen purposely in all respects as a governance solution to one or more social dilemmas. Two is that systems of exclusivity governed via market exchange and systems of state supply largely did not exist in anything approaching their modern forms during the time periods in question. In fact, the opposite is true. The end of the Republic of Letters, both in the sense of its transition into the Enlightenment and in the sense of its purpose or value, is often described in terms of the rise of nationalism and state support for scientific institutions (Burke 2012), on the one hand, and more robust scientific and industrial specialization, on the other hand, leading to greater investment in 
recognizably modern scientific organizations (research universities, scientific articles, peer review) and to accelerated economic growth (Mokyr 2017).

The most accurate way to describe the relative success and impact of the Republic of Letters as knowledge commons governance is that the Republic became and sustained itself, until it did not, and that the practices and values of the Republic of Letters evolved later, mostly productively, in ways that allow us to recognize their descendants today. That judgment is not to suggest that the Republic of Letters had an inertia of its own, independent of the energy of its citizens. Rather, the description of actors, norms, and practices elicited by the knowledge commons framework implies that it was a network of individuals comprising a collective or community, imprecisely defined (Strathern 1996; Margócsy 2017). Because of its relative openness, the Republic of Letters may be characterized institutionally as a community of practice (Brown and Duguid 1991; Wenger 2010). Its distributed form suggests combining those views via a final amendment: the Republic of Letters was a successful network of practice (Duguid 2005). The network label highlights its fragility; calling the Republic of Letters a community highlights its robustness.

The knowledge commons framework adds supplies nuance to this summary, for clarity. Each added layer of analysis contributes additional perspective but not a comprehensive or final evaluation.

\subsubsection{The Production of Knowledge}

The best place to begin is by treating knowledge as an intrinsic good. Characterized in material terms, the Republic of Letters left a significant legacy of knowledge-generating institutions and practices, and intellectual content. Many of the academies, learned societies, and journals established during that era have survived to the present day, although in modified form, and remain leading institutions of scientific collaboration and communications. Thousands of letters survive.

Characterized in immaterial terms, as to the tacit aspects of the Republic of Letters, its values and practices likewise endure. Public circulation of scientific research results, critique of the work using objective criteria based on merit rather than status, and the exercise of public debate and reasoned analysis by communities of trained experts remain central normative ideals of modern science. That remains the case, and it remains part of the legacy of the Republic of Letters, even if modern science and scientists do not always live up to those ideals, and even if, as the earlier review of twenty-first century open science illustrated, new threats and challenges to those ideals are often present. But the central dilemmas addressed by the Republic of Letters, consisting of developing the conceptual as well as technical tools needed to aggregate individual scientific knowledge into something called "science," remain the subjects of vigorous investigation. 
The propositional and codified dimensions of the knowledge produced during the Republic of Letters are more difficult to assess. The influence of some of its citizens on the development of science was enormous and enduring, Newton being perhaps the easiest case. The influence of many others was either significantly smaller or less enduring, or both. Of these, some are well-known to historians of science (Grafton 2008), others are known principally as exemplars of the types of individuals who were active participants of the time (Brockliss 2002). Still others occupy both camps, particularly the women of the Republic of Letters (Pal 2012).

\subsubsection{The Production of Value}

Knowledge, particularly scientific knowledge, also has instrumental and functional value. Joel Mokyr's examination of the Republic of Letters as a knowledge commons has approached the topic primarily from the standpoint of economics. He argued that the Republic of Letters created an engine of knowledge production that contributed significantly to economic growth in the eighteenth and nineteenth centuries, primarily via what today we would refer to as spillover effects (Mokyr 2011-2012, 2017). Mokyr called the Republic of Letters "one of the taproots of European technological change" and sustainable economic growth (a link that he cements via the phrase a "culture of growth"), in its influence on the Enlightenment and later on the Industrial Revolution. Anthony Grafton, too, analogized the Republic of Letters to a market for ideas rather than a community or collective of knowledge or knowledge producers (Grafton 2008). His reading is not motivated by economic understanding, like Mokyr, but it shares Mokyr's interest in the sources and impacts of the circulation of knowledge.

\subsubsection{The Production of Community and Identity}

Rather than prioritizing the production and dissemination of knowledge itself, focusing on communal identity and interest is an additional, distinct mode of assessing commons governance in this case. The Republic of Letters unambiguously articulated a scientific collective and unambiguously articulated the concept of the practitioner operating within and identifying with a scientific collective. That is so even if, in both respects, the precise contours of the collective and the precise definition of the scientific identity were fluid and evolutionary. The practices of the Republic of Letters produced both, over time. In this instance as in others, both the existence of a bounded network of practitioners and the porosity and fluidity of those boundaries are among its essential attributes (Strathern 1996). Similar analyses of community governance and the production of scientific or technical identity in knowledge commons settings have been undertaken with respect to modern technology, including the practice of citizen 
science in the Galaxy Zoo astrophysics project (Madison 2014) and governance of open source computer software collectives (Kelty 2008; Schweik and English 2012). Christopher Kelty's concept of the "recursive public," a phrase that denotes a distributed collective that constitutes its own identity via public practice of norm-bound technical skills, seems particularly apt with respect to the Republic of Letters.

The historian of science Mario Biagioli offered economies of prestige and reputation as significant motivators of the practices of both patrons in the Republic, who benefitted from public imputation of the accomplishments of "their" scientists, and citizens of the Republic, whose stature derived in part from their association with wealthy and high status patrons (Biagioli 1989, 1990). The developing prestige of scientific research was neither sufficient in itself to get the Republic of Letters under way nor to sustain it over time, either in individual or collective settings. But the Republic of Letters validated reputational considerations in the construction of scientific identity and community, as they interacted with resolution of disputes about priority, among other things (Merton 1957; Polanyi 1962).

\subsubsection{Costs}

Costs and harms should be accounted for, along with value and benefit. Normdriven and community-based governance generally poses risks of internalizing benefits for members and participants, and externalizing harms for others. Power dynamics and hierarchies may distort the workings of the group both within the collective and at the boundary between insiders and outsiders. The porosity of community and network boundaries and the informality of normgoverned systems create risks of opportunism and defection that may be particularly difficult to police, even while they enable a diverse range of positive spillovers. Communities of experts and elites both rely on and perpetuate exclusionary reputation and status economies. Among the challenges associated with contemporary open science is expanding the domain of effective scientific communications so that the character and benefits of open science appropriately includes non-experts (Royal Society (Great Britain), Science Policy Centre, and Royal Society (Great Britain) 2012).

Notably, Peter Gay claimed that the Republic of Letters enabled powerful patrons (in his account, oligarchs) to structure and control the flow of knowledge, particularly cultural knowledge (Gay 1966). That represents a significant cost of the Republic as a norm-driven, collectively managed enterprise, even if it is far from clear that those costs could have been avoided at the time. State-related investment in support for scientific research and communications got its start in and as part of the Republic of Letters, via scientific academies. Formal exclusive rights to be traded in markets, as incentives to invest and engage in knowledge production and dissemination, were just finding their toeholds during the 
Republic. Informal exclusivities, such as the secrecy practiced by craft guilds, spoke to different knowledge domains. Research universities, the modern equivalents of seventeenth and eighteenth century scientific patrons and similarly situated in ecologies of governance of shared knowledge resources, likewise preach values of community and knowledge sharing, but together with market-based enterprises and the expectations of modern patent law, universities exercise significant practical control over the flow of research and research results. And universities in the time of the Republic of Letters had not yet matured into research-based enterprises (Madison, Frischmann, and Strandburg 2009).

The fact that citizenship in the Republic of Letters was comparatively open, informal, and merit-based should not obscure the fact that participation was weighted heavily in favor of men, in favor of educated men at a time when education was accessible only to the few, and in favor of men with the means and opportunity to engage in study, reflection, preparation of correspondence, and participation in in-person meetings and visits. That characterization is not intended to diminish the contributions of the Republic of Letters in any respect other than to note that the institutional arrangement of actors, capabilities, and practices in an expertise-based field such as science was, and remains, contingent. The account earlier emphasized the breadth and heterogeneity of scientific interest within in the Republic of Letters. This brief account of demographics and material resources suggests a corresponding level of homogeneity. Which contributed and in which respects to the Republic's overall system of values and practices is open for debate. That debate continues. Modern practices of citizen science and substitution of "peer produced" industrial goods for firm-based production prompt examination of essentially identical questions of who participates and how, and with what results (Benkler 2017).

\subsection{The PRIVATE ORIGINS OF THE REPUBLIC OF LETTERS}

"Privacy" grounded in information about a person appears not to be part of the Republic of Letters as knowledge commons governance. One might examine scientists' letters themselves for indications that some of their contents were to be marked off as "private" and others as "public" or shareable, but on the whole, that sort of evidence is not present (Atkinson 1999). The style and content of the material products of the Republic of Letters is highly consistent with the era's emphasis on politeness and civility. While the letters themselves were far more conversational in style and character than modern propositional scientific articles, the contents were stylized and ritualized to align with the normative ambitions of the age.

Yet privacy interests and practices in material forms played key parts in the construction of the Republic of Letters. Letters themselves were sealed to protect their contents from disclosure other than to their intended recipients. But in the 
context of the Republic, letters were not intended to transmit intimate or possibly objectionable or unformed thoughts, as modern letter writing sometimes does. Letters to periodicals were intended to be adapted for publication. Writers of letters to other individuals expected their contents to become part of the circulating corpus of scientific knowledge. The physical spaces of private activity played the sorts of roles in the Republic of Letters that their counterpart spaces play today. Scientists conducted observations and prepared letters and manuscripts in private laboratories, libraries, and personal studies.

The most significant private resource developed and shared in the Republic of Letters was immaterial: the habit of personal and private thought and reflection that formed the practice of public reason and the style of objective disagreement and disputation for which the Republic of Letters was celebrated. The private resource in question was epistemological and conceptual, rather than material. It began in the mind of individual citizens of the Republic. It was materialized through the letters themselves. Via the circulation of print, what was necessarily an individual's capacity for reasoned analysis became a collectively managed, shared resource. What we would today call private scientific thought, the Baconian style and strategy, became a public good. The Republic of Letters emerged from the minds as well as the hands of its individual practitioners.

The pivotal character in this development, explaining both the problem and his understanding of the solution, was Immanuel Kant. The challenge was freedom itself, as in humankind's release from its self-incurred immaturity, "the inability to use one's own understanding without the guidance of another" (Kant 1996). Kant identified enlightenment with the process of thinking for oneself, employing and relying on one's own intellectual capacities in determining what to believe and how to act. In the essay "What is Enlightenment?," published in 1785, Kant described what he described as the distinction between "public" reason and "private" reason (Kant 1996). The "private" use of reason, in Kant's framing, consisted of the activities and contributions of individuals acting in their capacities as agents or officers of the state, or the military service, or the church. To protect the interests of the community of which the individual was a part, the state could, Kant believed, legitimately restrain the exercise of that "private" faculty. By contrast, the "public" use of reason was the capacity of individuals to think for themselves, without being bound by accepted historical authorities, inherited learning, or patterns of thought - or, in short, enlightenment. As to individuals using those faculties, the state could not legitimately censor "public" communications.

But enlightenment itself required community, and a community of a particularly new sort: a universal community, one not defined by institutional hierarchy, role, and domination, circumscribed locally or territorially. When Kant wrote that "the public should enlighten itself," he anticipated a community with open participation. And when he wrote, "[b]y the public's use of one's reason I understand the use which a person makes of it as a scholar before the reading 
public," thinking for themselves, communicating in their own names, and engaging in dialogue with other learned men, as their peers, Kant had in mind the Republic of Letters (Chartier 1991).

In sum, Kant suggested that the practices of the Republic of Letters evidenced the conversion of what in modern terms would be considered private thought into a collectively produced public resource, a resource defined philosophically and epistemologically rather than materially. And that public resource was itself both a critical contribution to and product of the Republic of Letters. It was the power to reason independently, with others.

The link between Kant's work and the Republic of Letters was highlighted when Kant's argument became the foundation for Habermas's concept of the "public sphere": a kind of publicness that Habermas argued came into being at the end of the seventeenth and beginning of the eighteenth centuries in Europe (Habermas 1989) and that was specifically associated with the emergence of public science with respect to both scholarship and industrial application (Stewart 1992; Jacob 1997; Mokyr 2017). Habermas defined the public sphere as private individuals coming together to make a public use of their reason via periodicals and the medium of print, and via salons and other social organizations. Habermas argued that until the era of the Republic of Letters, a conception of publicness as reasoned debate open to all literally did not exist even if it was limited to learned society rather than to "the public" as a whole. Outside of the institutions of the state and the church, individuals did not have the political freedom, the conceptual tools, or the material devices to engage in reasoned analysis of their worlds (the Baconian point), to believe that they could and should share that analysis with others (the Kantian point), or to be able to actively take steps to construct the boundaries and links that developed between private thought and behavior and a construct of the public (Habermas' conclusion).

Private thought and reflection independent of the legacy institutions of state and society, or what Kant framed as "public" reason, therefore both supplied and was the product of the shared immaterial and material knowledge of the Republic of Letters. Private reflection was infrastructure, in the sense that it enabled virtually all of what followed via public circulation of scientific material, but private reflection, as infrastructure, was also the product of public circulation of scientific material. This is the sense in which the Republic of Letters constituted itself, as an identity, as a collective, and as a set of practices. It is also the sense in which private thought and reflection contributed and constituted a key Republic of Letters resource (Kuchar and Dekker 2021).

A brief schematic description of the respective roles of the private and the public in practice, moving up and down the register of personal and collaborative or shared activity, makes the point more concrete. The description evokes the earlier reference to how communications theory itself may explain certain features of the social dilemmas present. 
To begin with, a citizen of the Republic had to learn and adopt an epistemological stance for himself relative to empiricism (his ability to learn new things about the world, for himself) and relative to the communitarian norms of the collective (his duty to share his work with friends, as colleagues and peers). This would be an act of learning, in which collective, shared knowledge would become personalized and privatized in the mind, and the act of the individual. Those acts would be combined with the related acts of interpreting and applying for himself related propositional knowledge and tacit or uncodified knowledge about particular scientific work. Conversing with a visitor or reading a letter from a correspondent, this citizen would form judgments about the character and reputation of the person, the character of the person's correspondents, the nature of the questions being considered, the state of related work being done by others, and what steps to take next.

These judgments would, in turn, form the basis of that citizen's own next acts and correspondence (Goldgar 1995), combining his private reaction to and reflection on what he had learned with his own collecting, observing, experimenting, and interpreting. The documented version, in public circulation, would prompt the next round of reaction, reflection, documentation, and circulation of material by others.

Material objects thus served critical roles in scaling the knowledge collective of the Republic of Letters up from the individual to the group, and then back down again. Those documents were books, letters, and their derivatives, such as news, extracts, and abstracts, which appeared in journals. Narratives were often accompanied by attachments and appendices in the form of drawings, diagrams, and tables (van Miert 2013). This latter category of material is particularly interesting in the context of the circulation and expansion of private reflection into public infrastructure. Bruno Latour refers to these printed representations of immaterial knowledge "things" as "immutable mobiles," because they simultaneously document and simplify individual engagement with nature as they circulate, permitting the exercise of faculties of collective acceptance and skepticism (Latour 1986). This is an important cognitive add-on to standard arguments about the significance of print to the development of science. The printed letter form served as both the medium of personal knowledge codification and transmission - the technological mechanism that documented solitary reflection and communicated trustworthiness in the person to the recipient and to the collective, so important to the Republic of Letters - as well as the means by which science eventually became objective and durable at scale, independent of the person.

\subsection{MODERN IMPLICATIONS}

The study of the Republic of Letters as knowledge commons reveals three noteworthy modern implications. The first has to do with the character and 
utility of the knowledge commons framework itself. This case study suggests some noteworthy strengths and weaknesses. The second has to do with the Republic of Letters and its early scientific community as knowledge commons governance. Careful examination of the Republic and its shared resources link certain existing lines of research more closely that they may have been linked previously, indicating some new directions for further examination of scientific practice. The third has to do with open science.

\subsubsection{The Future of the Knowledge Commons Framework}

The knowledge commons framework has been described from the beginning as a research device, a heuristic akin to Ostrom's IAD framework for collecting data in a structured and systematic way (Madison, Frischmann, and Strandburg 2010). Theorizing and modeling of knowledge commons have been deferred, and the framework is not intended to be used as a set of rules or guidelines for constructing viable or successful knowledge commons governance.

Nevertheless, given the conceptual affinities between the knowledge commons framework and the IAD framework (Ostrom 1990), it has been difficult for many to avoid the instinct that Ostrom's guidelines for successful commons practice ought to inform application of the knowledge commons framework. Noteworthy among those guidelines are the ideas that successful commons requires a well-bounded community with a clear consumption pattern relative to the resource at hand, and that the community ought to have well-managed systems for monitoring consumption and for disciplining inappropriate behavior. The knowledge commons framework itself directs researchers to identify and evaluate systems of boundary management, resource monitoring, and discipline.

For legal scholars drawn to Ostrom's vision in knowledge-based settings, the instinct to define the scope of commons governance with relative specificity are echoed in research on social norms and property management, which indicates that community self-governance is likely to be effective (welfare-maximizing, in economic terms) only in small, close-knit, relatively homogenous collectives (Darling and Perzanowski 2017; Oliar and Sprigman 2008).

Against that background, the Republic of Letters disappoints. It did not constitute a well-bounded membership community, it had few shared mechanisms for monitoring resource production and consumption, and its disciplinary practices relied as much or more on implicit appeals to the shared values of civility and publicness as on explicit dispute resolution processes. The open-endedness of the Republic of Letters explains, in part, the appeal of metaphors drawn from exclusivity-based market exchange (the Republic of Letters as a market of and for ideas (Grafton 2008)), anachronistic though that metaphor obviously is. The anachronism is telling: the Republic of Letters emerged at a time when state institutions for knowledge production were 
primitive, and market-based alternatives, such as patents and copyrights, were just starting to displace guild practice.

Yet the assumption that precise boundaries are necessary to effective commons governance may be mistaken. The search for boundaries and boundedness is necessary and appropriate, because only via the search can researchers determine the relevance of the results across different cases and contexts. Earlier work applying the knowledge commons framework suggested the utility of the framework to atypical cases of knowledge commons (Frischmann, Madison, and Strandburg 2014a). Those cases indicate that knowledge commons governance may flourish even in the absence of features that might, in other settings, be deemed essentially necessary, such as firm boundaries, and systems for monitoring and disciplining resource overconsumption. The case of the Republic of Letters affirms that finding, and in doing so it affirms the core insight motivating knowledge commons research: governance systems for shared resources are best understood via nuanced understanding of the social dilemmas to which they relate. Earlier, the chapter explained the insufficiency of the "tragedy of the commons" metaphor to describe social dilemmas concerning knowledge and information resources. Relevant social dilemmas for knowledge commons tend to collect around ideas of collaborative participation and contribution, as well as or as alternatives to production.

The knowledge commons framework has not, however, emphasized sufficiently the roles that shared conceptual infrastructures can play in knowledge commons, as they do in the Republic of Letters. Many infrastructural resources are governed as commons, not in the sense that Ostrom's work documented commons governance that solved tragic commons dilemmas, but in the sense that the legal scholar Carol Rose described shared material resources, such as roads, as "the more the merrier" settings, where the social benefits of shared access multiply as more and more people use the resource. Maximizing social value in that setting justifies governance via commons mechanisms (Rose 1986; Frischmann 2012). The Republic of Letters should be characterized as both having relied on shared infrastructural resources, particularly the epistemological developments described in the last section, and having produced shared infrastructural resources, in the form of scientific community as a social fact.

\subsubsection{The Future of the Republic and the Organization of Science}

The institutional evolution of scientific research and scientific communities continued after the end of the Republic of Letters and continues today. The evolution of organizational pathways signified by and in some respects initiated during the Republic of Letters is well-known. Learned societies and academic journals coevolved with research universities and scientific specializations 
through the eighteenth and nineteenth centuries. Funding mechanisms took on a more complex and diverse character, as patronage systems and private sponsorship even inside universities were eventually displaced by formal state support (outside the United States) and by blends of state support and philanthropy (in the United States). The practice of scientific research in the later nineteenth century distinguished between basic and applied research, the former practiced largely in universities and research institutes, and the latter practiced in industrial research and development organizations. Norms of civility were gradually displaced by ever-more-formal systems of peer review as a mechanism for ensuring trust and objectivity in scientific results.

The knowledge commons framework should remain a useful tool for diagnosing problems and institutional solutions with respect to the evolution of social dilemmas in different aspects of scientific research, and in particular questions of what is "inside" self-governed scientific communities and what is "outside," possibly governed differently. The research university is one particularly fruitful case (Madison, Frischmann, and Strandburg 2009). It offers a powerful illustration of polycentricity and the interweaving of multiple governance systems at different organizational levels, for different purposes.

Evolution of shared values and conceptual frameworks has proceeded differently, and some would say has proceeded with less variation over time and across institutional settings. Robert Merton and Michael Polanyi each proffered essentially universal accounts of the norms of open, objective, and communitarian scientific research (Merton 1942; Polanyi 1962). Constructivist accounts of science, by scholars including Thomas Kuhn, Bruno Latour, and Etienne Wenger focused instead on the variability of social and material conditions underlying scientific production (Latour and Woolgar 1986; Wenger 2010; Kuhn 2012). Latour in particular was sensitive to the social and material implications of the changing epistemological foundations of scientific research that the Republic of Letters embodied. Wenger shifted the analytic lens from an idealized community of openness to a pragmatic community of shared practice. One implication of this study is that researchers using the knowledge commons framework should excavate shared knowledge resources down to the level of the mind of the individual researcher. The work of Kuhn, Latour, and Wenger offers different ways to link the results of that excavation to the specifics of scientific practice. Science may be normatively public, but the idea of the private is embodied in multiple models of scientific behavior. Further research may disclose others, in the new light of knowledge commons.

\subsubsection{Open Science Reconsidered}

A final implication of the study of the Republic of Letters builds on that note about the changing embodiments of public and private interests in scientific knowledge commons. Open science, the modern combination of technologies, funding 
strategies, and publication systems in which the chapter situated its interest in the Republic of Letters, is likewise concerned with appropriate blends of public and private interests. An implication of the present work is that the contemporary meanings and significance of those terms may differ from their importance historically. The practical embodiments operate at both explicit and tacit layers and polycentric organizational and institutional settings.

To modern ears, the interwoven ideas of public and private often connote sectoral settings. Public interest is identified with the state, and with the intuition that the institutions of the state are designed to enact and support the interests of the public as a whole, as a collective. Private interest and private actors are non-state-related. They draw their foundations and legitimacy from law, either as entities or as individuals, but law codifies their capacity for acting as they wish, for their own benefit or for others'. The modern concept of privacy enforces a set of norms that partly protects the second group of interests (private actors) from overreaching by the first (the state, and the collective) and that partly protects members of the second group from overreaching by other members.

As applied to modern knowledge and information production, that syntax is often translated concretely into a set of specific concerns relevant to governance questions. Those questions include the extent to which knowledge and information resources should be governed as private resources or private goods: patents, or copyrights. Open means public, and public means open, and idealized. Private means the market, and privacy as such means personal. Each governance strategy, whether public or private, may be understood in relation to corresponding social dilemmas.

The implications of the study of the Republic of Letters, drawing on the summary earlier of Kant's writing about science and public and private uses of reason, is that this syntax and the accompanying concepts and practices are, like the material conditions of scientific practice, porous and changeable. The immaterial goals and values of science may change with the organizational settings of science but not necessarily at the same pace or in the same direction. The question for open science today is in part the boundary between presumptively open scientific research shared in the research setting, and presumptively private scientific research disclosed via systems of exclusive right - technology transfer practices, encoding patent law and market expectations. Can open science move that boundary more in the direction of public and open access and impact? In part that is a question of materiality and organizational design. The Republic of Letters suggests that it is also a question of immateriality and the syntax of shared values.

The Republic of Letters operated as a set of norms pulling scientific knowledge out of the mind, the library, and the laboratory and into a shared collective setting. Kant (and later Habermas) called this practice the "public" use of reason. Patent law, today, is the counterpart institution, "pulling" scientific research out of the university laboratory and into the marketplace (Frischmann 
2009). The "pull" is from the construct that today we call public to the construct that today we call private. These are different governance systems relating to overlapping but distinct social dilemmas. Fully modernizing the material and conceptual apparatus of scientific research to achieve the hoped-for benefits of open science suggests recasting at least some of those public and private constructs. One possible pathway forward is recalibrating the conceptual foundations of the major organizations of scientific research research universities themselves -as to both the social dilemmas they embody and the governance strategies they advance. As universities have matured over the last 100 years, and especially since World War II, they have gotten ever more enmeshed in the rhetoric and practice of intellectual property as a governance solution to one set of university-related social dilemmas - to wit, how to maximize the social benefit associated with university-based scientific research funded by the public sector?

That boundary between public and private, in short, is defined today by a governance solution (intellectual property) to a social dilemma (public access to scientific research results). That solution has become the very thing that some argue needs to be displaced, going forward, to realize the ambitions of open science (Madison 2019). A governance strategy that addressed one social dilemma has generated another social dilemma. The system is, in a word, dynamic. The implication of the present study is not that open science justifies a return to the conceptual framework observed beneath the Republic of Letters, let alone to Kant, or Habermas. Instead, the implication is this: the way forward need not depend on the terms on which the social dilemmas of research science have proceeded historically. The concepts of publicness, private interest, and privacy are tools with which the resources, collectives, and rules of governance may be both stabilized and reconstituted in new material settings. One scholar describing the potential for economic impact associated with twenty-first century science refers to the enterprise as the "new invisible college," explicitly invoking a metaphor for scientific collaboration that may have predated the Republic of Letters (Wagner 2008). In open science, analysis and advocacy should focus on the character of relevant governance relationships and on boundary construction and boundary management - what is inside and what is outside; how different governance institutions are linked to one another; what (and who) is infrastructure and what is application - rather than solely on the science itself, as an object. Governance may produce publicness and privateness, not simply manage them.

\subsection{CONCLUSION}

This chapter has extended the knowledge commons research framework to an early historical case of scientific research: the Republic of Letters, an extended communications network of scientists that flourished across Europe in the 
sixteenth, seventeenth, and eighteenth centuries. The defining character of the Republic was its normative emphasis on public dissemination of scientific knowledge via both formal and informal communications networks, including circulation of books and letters, the production of early scientific journals, and face to face conversation.

The chapter draws particular attention to the role of private interests and private research in the production of the Republic's shared publicness and collective of scientific knowledge. The Republic of Letters was characterized by early forms of the personal and private reason at the level of and in the mind of the individual scientist, which had to be shared via communications and communication networks to form the publicly shared epistemological infrastructure of modern science. The chapter links those practices to Kantian philosophy, which explains the significance of shared private contributions and private reason in the context of community-based scientific knowledge governance.

The concept of private reason as a shareable knowledge resource in knowledge commons terms is new. For modern scientific knowledge production, which is concerned in many respects with the concept of open science, the chapter suggests that attention to openness must always be tempered by the fact that openness may depend on critical if sometimes concealed personal and private resources.

\section{REFERENCES}

Anderson, Benedict R. O'G. 1983. Imagined Communities: Reflections on the Origin and Spread of Nationalism. London: Verso.

Atkinson, Dwight. 1999. Scientific Discourse in Sociohistorical Context: The Philosophical Transactions of the Royal Society of London, 1675-1975. Rhetoric, Knowledge, and Society. Mahwah, NJ: L. Erlbaum Associates.

Baldwin, Melinda. 2017. "In Referees We Trust?" Physics Today 70 (2): 44-49. https://doi.org /10.1063/PT.3.3463.

2018. "Scientific Autonomy, Public Accountability, and the Rise of 'Peer Review' in the Cold War United States." Isis 109 (3): 538-558. https://doi.org/10.1086/700070.

Benkler, Yochai. 2017. "Law, Innovation, and Collaboration in Networked Economy and Society." Annual Review of Law and Social Science 13 (1): 231-250. https://doi.org/10.1146 /annurev-lawsocsci-110316-113340.

Biagioli, Mario. 1989. "The Social Status of Italian Mathematicians, 1450-1600." History of Science 27 (1): 41-95. https://doi.org/10.1177/007327538902700102.

1990. “Galileo's System of Patronage." History of Science 28 (1): 1-62. https://doi.org/10.1177 /007327539002800101.

Blair, Ann. 2010. Too Much to Know: Managing Scholarly Information before the Modern Age. New Haven: Yale University Press.

Borgman, Christine L. 2015. Big Data, Little Data, No Data: Scholarship in the Networked World. Cambridge, MA: MIT Press.

Brockliss, L. W. B. 2002. Calvet's Web: Enlightenment and the Republic of Letters in EighteenthCentury France. Oxford: Oxford University Press. 
Brown, John Seely and Paul Duguid. 1991. "Organizational Learning and Communities-of Practice: Toward a Unified View of Working, Learning, and Innovation." Organization Science 2 (1): 40-57. https://doi.org/10.1287/orsc.2.1.40.

2000. The Social Life of Information. Boston: Harvard Business School Press.

Burke, Peter. 2012. "The Republic of Letters as a Communication System." Media History 18 (3-4): 395-407. https://doi.org/10.1080/13688804.2012.721956.

Chartier, Roger. 1991. The Cultural Origins of the French Revolution. Translated by Lydia G. Cochrane. Durham: Duke University Press.

Darling, Kate and Aaron Perzanowski, eds. 2017. Creativity without Law: Challenging the Assumptions of Intellectual Property. New York: NYU Press.

Darnton, Robert. 2003. George Washington's False Teeth: An Unconventional Guide to the Eighteenth Century. New York: W W Norton \& Co.

Daston, Lorraine. 1991. "The Ideal and Reality of the Republic of Letters in the Enlightenment." Science in Context 4 (2): 367-386. https://doi.org/10.1017 /S0269889700001010.

1994. "Baconian Facts, Academic Civility, and the Prehistory of Objectivity." In Rethinking Objectivity, edited by Allan Megill, 37-64. Durham: Duke University Press.

David, Paul. 2008. "The Historical Origins of 'Open Science': An Essay on Patronage, Reputation and Common Agency Contracting in the Scientific Revolution." Capitalism and Society 3 (February): 5-5. https://doi.org/10.2202/1932-0213.1040.

David, Paul, Matthijs den Besten, and Ralph Schroeder. 2008. "Will E-Science Be Open Science?" SIEPR Discussion Paper No. 08-10. https://siepr.stanford.edu/research/publi cations/will-e-science-be-open-science.

Dear, Peter. 1992. "From Truth to Disinterestedness in the Seventeenth Century." Social Studies of Science 22 (4): 619-631.

DiMaggio, Paul and Walter W. Powell. 1983. "The Iron Cage Revisited': Institutional Isomorphism and Collective Rationality in Organizational Fields." American Sociological Review 48: 147-160.

Duguid, Paul. 2005. "The Art of Knowing': Social and Tacit Dimensions of Knowledge and the Limits of the Community of Practice." The Information Society 21 (2): 109-118. https:// doi.org/10.1080/01972240590925311.

Eamon, William. 1996. Science and the Secrets of Nature: Books of Secrets in Medieval and Early Modern Culture. Princeton: Princeton University Press.

Eden, Kathy. 2001. Friends Hold All Things in Common: Tradition, Intellectual Property, and the Adages of Erasmus. New Haven: Yale University Press.

Frischmann, Brett M. 2009. "The Pull of Patents." Fordham Law Review 77 (5): 2143-2167.

2012. Infrastructure: The Social Value of Shared Resources. New York: Oxford University Press.

Frischmann, Brett M., Michael J. Madison, and Katherine J. Strandburg. 2014a. "Governing Knowledge Commons." In Governing Knowledge Commons, edited by Brett M. Frischmann, Michael J. Madison, and Katherine J. Strandburg, 1-43. New York: Oxford University Press.

Frischmann, Brett M., Michael J. Madison, and Katherine J. Strandburg, eds. 2014b. Governing Knowledge Commons. Oxford; New York: Oxford University Press.

Fumaroli, Marc. 1988. “The Republic of Letters.” Diogenes 36 (143): 129-152. https://doi.org/10 $.1177 / 039219218803614307$.

2018. The Republic of Letters. Translated by Lara Vergnaud. New Haven: Yale University Press.

Gay, Peter. 1966. The Enlightenment: An Interpretation. Volume 2: The Science of Freedom. New York: W W Norton \& Co.

Geison, Gerald L. 2014. Private Science of Louis Pasteur. Princeton: Princeton University Press. 
Goldgar, Anne. 1995. Impolite Learning: Conduct and Community in the Republic of Letters, 1689-1750. New Haven: Yale University Press.

Goodman, Dena. 1996. The Republic of Letters: A Cultural History of the French Enlightenment. Ithaca: Cornell University Press.

Grafton, Anthony. 2008. "A Sketch Map of a Lost Continent: The Republic of Letters." Republics of Letters 1 (1). https://arcade.stanford.edu/rofl/sketch-map-lostcontinentrepublic-letters.

2009. Worlds Made by Words: Scholarship and Community in the Modern West. Cambridge: Harvard University Press.

Greif, Avner and Joel Mokyr. 2016. "Cognitive Rules, Institutions, and Economic Growth: Douglass North and Beyond." Journal of Institutional Economics 13 (1): 25-52. https://doi .org/10.1017/S1744137416000370.

Habermas, Jürgen. 1989 [1962]. The Structural Transformation of the Public Sphere: An Inquiry into a Category of Bourgeois Society. Translated by Thomas Burger. Cambridge: The MIT Press.

Hindley, Meredith. 2013. "Mapping the Republic of Letters." Humanities 34 (6). www .neh.gov/humanities/2013/novemberdecember/feature/mapping-the-republic-letters.

Hutchins, Edwin. 2000. Cognition in the Wild. Cambridge: The MIT Press.

Jacob, Margaret C. 1997. Scientific Culture and the Making of the Industrial West. New York: Oxford University Press.

Johns, Adrian. 2009. Piracy: The Intellectual Property Wars from Gutenberg to Gates. Chicago: University of Chicago Press.

Kant, Immanuel. 1996 [1784]. "What Is Enlightenment?" In What Is Enlightenment? Eighteenth-Century Answers and Twentieth Century Questions, edited by James Schmidt. 5864. Berkeley: University of California Press.

Kelty, Christopher M. 2008. Two Bits: The Cultural Significance of Free Software. Experimental Futures. Durham: Duke University Press.

Knorr-Cetina, K. 1999. Epistemic Cultures: How the Sciences Make Knowledge. Cambridge: Harvard University Press.

Kuchar, Pavel and Erwin Dekker. Forthcoming. "Governing Markets as Knowledge Commons: Introduction." In Governing Markets as Knowledge Commons. Cambridge: Cambridge University Press.

Kuhn, Thomas S. 2012 [1962]. The Structure of Scientific Revolutions. 4th ed. Chicago, IL: University of Chicago Press.

Latour, Bruno. 1986. "Visualization and Cognition: Thinking with Eyes and Hands." In Knowledge and Society: Studies in the Sociology of Culture Past and Present: A Research Annual, edited by Elizabeth Long and Henrika Kuklick, 6:1-49. Greenwich, CT: JAI Press.

Latour, Bruno and Steve Woolgar. 1986. Laboratory Life: The Construction of Scientific Facts. Princeton: Princeton University Press.

Long, Pamela 0. 1991. 'Invention, Authorship, 'Intellectual Property,' and the Origin of Patents: Notes toward a Conceptual History." Technology and Culture 32 (4): 846-84. https://doi.org/10.2307/3106154.

Maclean, Ian. 2008. "The Medical Republic of Letters before the Thirty Years War." Intellectual History Review 18 (1): 15-30. https://doi.org/10.1080/17496970701819327.

Madison, Michael J. 2014. "Commons at the Intersection of Peer Production, Citizen Science, and Big Data: Galaxy Zoo." In Governing Knowledge Commons, edited by Brett M. Frischmann, Michael J. Madison, and Katherine J. Strandburg, 209-254. New York: Oxford University Press. 
Michael J. Madison, The Republic of Letters and the Origins of Scientific Knowledge Commons 34

2019. "Data Governance and the Emerging University." In Research Handbook on Intellectual Property and Technology Transfer, edited by Jacob H. Rooksby, 364-390. Cheltenham, UK: Edward Elgar Publishers.

Madison, Michael J., Brett M. Frischmann, and Katherine J. Strandburg. 2009. "The University as Constructed Cultural Commons." Washington University Journal of Law and Policy 30: 365-403.

2010. "Constructing Commons in the Cultural Environment." Cornell Law Review 95 (4): 657-709.

Margócsy, Dániel. 2017. “A Long History of Breakdowns: A Historiographical Review." Social Studies of Science 47 (3): 307-325. https://doi.org/10.1177/0306312717706559.

Merton, Robert K. 1938. "Science and the Social Order." Philosophy of Science 5 (3): 321-337.

Merton, Robert K. 1942. "Science and Technology in a Democratic Order." Journal of Legal and Political Sociology 1: 115-126.

1957. "Priorities in Scientific Discovery: A Chapter in the Sociology of Science." American Sociological Review 22 (6): 635-659.

Miert, Dirk van, ed. 2013. Communicating Observations in Early Modern Letters (1500-1675): Epistolography and Epistemology in the Age of the Scientific Revolution. London: Warburg Institute.

Miert, Dirk van. 2016. "What Was the Republic of Letters? A Brief Introduction to a Long History." Groniek, 204, (5): 269-287. https://ugp.rug.nl/groniek/article/view/27601.

Mokyr, Joel. 2011-2012. "The Commons of Knowledge: A Historical Perspective," The Annual Proceedings of the Wealth and Well-Being of Nations IV: 16.

2017. A Culture of Growth: The Origins of the Modern Economy. Princeton: Princeton University Press.

National Academies of Sciences, Engineering, and Medicine (U.S.), National Academies of Sciences, Engineering, and Medicine (U.S.), National Academies of Sciences, Engineering, and Medicine (U.S.), and National Academies of Sciences, Engineering, and Medicine (U.S.), eds. 2018. Open Science by Design: Realizing a Vision for 21st Century Research. A Consensus Study Report. Washington, DC: The National Academies Press.

North, Douglass C. 1990. Institutions, Institutional Change, and Economic Performance. Cambridge: Cambridge University Press.

Oliar, Dotan and Christopher Sprigman. 2008. “There's No Free Laugh (Anymore): The Emergence of Intellectual Property Norms and the Transformation of Stand-up Comedy." Virginia Law Review 94 (8): 1787-1867.

Ostrom, Elinor. 1990. Governing the Commons: The Evolution of Institutions for Collective Action. Cambridge: Cambridge University Press.

Padgett, John Frederick and Walter W Powell. 2017. The Emergence of Organizations and Markets. http://dx.doi.org/10.23943/princeton/9780691148670.001.0001.

Pal, Carol. 2012. Republic of Women: Rethinking the Republic of Letters in the Seventeenth Century. Cambridge: Cambridge University Press.

Polanyi, Michael. 1962. "The Republic of Science: Its Political and Economic Theory." Minerva 1 (1): 54-73.

Polanyi, Michael. 1966. The Tacit Dimension. Chicago: University of Chicago Press.

Porter, Theodore M. 1996. Trust in Numbers: The Pursuit of Objectivity in Science and Public Life. Princeton: Princeton University Press.

Powell, Walter W. 1990. "Neither Market nor Hierarchy: Network Forms of Organization." Research in Organizational Behavior 12: 295-336.

Rose, Carol M. 1986. "The Comedy of the Commons: Commerce, Custom, and Inherently Public Property." University of Chicago Law Review 53 (3): 711-781. 
Royal Society (Great Britain), Science Policy Centre, and Royal Society (Great Britain). 2012. Science as an Open Enterprise. https://royalsociety.org/ /media/royal_society_content/ policy/projects/sape/2012-06-20-saoe.pdf.

Schweik, Charles M. and Robert C. English. 2012. Internet Success: A Study of Open-Source Software Commons. Cambridge: The MIT Press.

Shapiro, Martin. 1972. "Toward a Theory of Stare Decisis." Journal of Legal Studies 1 (1): 125-34.

Spender, J. C. 1996. "Making Knowledge the Basis of a Dynamic Theory of the Firm." Strategic Management Journal 17 (S2): 45-62. https://doi.org/10.1002/smj.4250171106.

Stewart, Larry. 1992. The Rise of Public Science: Rhetoric, Technology, and Natural Philosophy in Newtonian Britain, 1660-1750. Cambridge: Cambridge University Press.

Stokes, Donald E. 2011. Pasteur's Quadrant: Basic Science and Technological Innovation. Washington, DC: Brookings Institution Press.

Strathern, Marilyn. 1996. "Cutting the Network." The Journal of the Royal Anthropological Institute 2 (3): 517-35.

Wagner, Caroline S. 2008. The New Invisible College: Science for Development. Washington, DC: Brookings Institution Press.

Wenger, Etienne. 2010. "Communities of Practice and Social Learning Systems: The Career of a Concept." In Social Learning Systems and Communities of Practice, edited by Chris Blackmore, 179-98. London: Springer London. https://doi.org/10.1007/978-184996-133-2_11.

Westfall, Richard S. 1977. The Construction of Modern Science: Mechanisms and Mechanics. Cambridge: Cambridge University Press.

Zuckerman, Harriet and Robert K. Merton. 1971. "Patterns of Evaluation in Science: Institutionalisation, Structure and Functions of the Referee System." Minerva 9 (1): 66-100. https://doi.org/10.1007/BF01553188. 